\title{
Experimental study of peripheral-blood pro-surfactant protein B for screening non-small cell lung cancer ${ }^{1}$
}

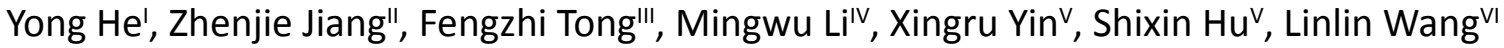

\begin{abstract}
'Master, Department of Thoracic Surgery, $5^{\text {th }}$ People's Hospital of Dalian, China. Conception of the study, interpretation of data, statistical analysis.

"Master, Department of Thoracic Surgery, People's Hospital of Dalian, China. Acquisition of data, statistical analysis.

'"'Master, Clinical Laboratory, People's Hospital of Dalian, China. Acquisition and interpretation of data.

"vachelor, Department of Thoracic Surgery, $5^{\text {th }}$ People's Hospital of Dalian, China. Acquisition and interpretation of data.

${ }^{\vee}$ Bachelor, Department of Thoracic Surgery, $5^{\text {th }}$ People's Hospital of Dalian, China. Acquisition of data, statistical analysis.

v'Bachelor, Matron, Department of Thoracic Surgery, $5^{\text {th }}$ People's Hospital of Dalian, China. Acquisition of data, statistical analysis.
\end{abstract}

\begin{abstract}
Purpose: To evaluate the possibility of using peripheral-blood presurfactant protein B (ProSFTPB) for screening non-small cell lung cancer (NSCLC).

Methods: A total of 873 healthy volunteers and 165 lung cancer patients hospitalized in the Fifth People's Hospital of Dalian were tested Pro-SFTPB once every half year from January 2014 to September 2015. The healthy volunteers were also conducted spiral computed tomography (CT) examination once every year. The data were then com-pared and statistically analyzed.

Results: The positive expression rate of Pro-SFTPB in NSCLC was significantly higher than that in healthy volunteers, and significantly higher in lung adenocarcinoma than in squamous cell carcinoma; additionally, the expression rate was increased with the in-crease of smoking index, and the intergroup differences showed statistical signifi-cance $(p \leq 0.05)$. The positive rate of newly diagnosed lung cancer was $29.55 \%$, higher than healthy volunteers (22.34\%), but there was no significant difference ( $p>0.05)$.

Conclusion: Pro-SFTPB is over expressed in non-small cell lung cancer, especially in lung adenocarcinoma, but it can't be used as a clinical screening tool for lung cancer.
\end{abstract}

Key words: Non-Small Cell Lung Cancer. Lung Neoplasms. Mass Screening. 


\section{Introduction}

In recent years, the incidence of lung cancer increases year by year, and it's still the primary cancer that causes death in China. The survival outcome of lung cancer patients depends more on their stages when diagnosed. Early detection and diagnosis is the key of improving the survival rate of lung cancer. Scholars have been various exploring means over years, aiming to improve the five-year survival rate of lung cancer through early diagnosis and treatment. The National Lung Screening Trial (NLST) data show that low-dose chest computed tomography (LDCT) scan for high-risk groups can reduce the total mortality by $20 \%$ and $7 \%$ in current and pre-smokers, re-spectively ${ }^{1}$. Japanese scholars have further improved the detection rate of pulmonary nodules by combining positron emission tomography (PET) and $\mathrm{LDCT}^{2,3}$. But in re-cent years, controversies about the application of LDCT for early lung cancer screening have also emerged. European Journal of Radiology reported that chest CT scans can cause osteoporosis and even spinal fractures ${ }^{4}$. Jubal also proposed CT scan for lung cancer screening may increase cardiovascular diseases, especially can accelerate coronary artery calcification $^{5}$. It has also been reported that LDCT used in lung cancer screening exhibited too many false-positive, overdiagnosed, and treated cases $^{6,7}$; therefore, exploring new effective lung cancer screening method has become a hotspot in medical fields. Some scholars have tried to achieve the purpose of early diagnosis by chromatographically analyzing the exhaled gases and secretions ${ }^{8}$. Studies about detecting blood tumor markers for screening lung cancer have been carried out for many years, but no target markers with high specificity and high sensitivity have been found ever ${ }^{9-12}$. At the same time, if LDCT-lung cancer screening was to applied to Chinese populations, it will bring great economic burden to the country, so exploring a simple and economical blood test screening method is particularly important.

Our previous studies have shown that Pro-SFTPB often presents in the peripheral blood of immaturely developed children and is associated with many chronic lung diseases, such as respiratory distress syndrome (RDS) ${ }^{13-}$ ${ }^{16}$, which may cause chronic lung dysfunction in chronic obstructive pulmonary disease (COPD) patients ${ }^{17}$. Mean-while, the abnormal regulation of surfactant protein $B$ in non-small cell lung cancer (NSCLC) may cause its overexpression of Pro-SFTPB. Dr. Ayumu Taguchi, MD, MD Anderson Cancer Center, University of Texas, USA (2013), showed that there is ab-normal SFTPB synthesis and regulation in breast tumors, especially in the adenocarci-noma cells, so Pro-SFTPB is overexpressed, and the modification ability of its pro-somes after being translated toward mature hydrophobicity will also occur mutation. Ayumu found that compared with the matched control, the level of mature SFTPB in the peripheral blood of surgery-treatable lung cancer patients is increased. The results of mass spectrometry screening has shown that the $\mathrm{N}$-terminal of the front peptide of SFTPB can be used as a potential biomarker for NSCLC. Ayumu established and veri-fied the enzyme-linked immunosorbent assay (ELISA) of blood Pro-SFTPB between surgery-treatable NSCLC patients and healthy controls. Preliminary studies have sug-gested that serum Pro-SFTPB levels may be associated with certain lung cancer-independent known clinical risk factors, and high levels of blood ProSFTPB may be used to evaluate the lung cancer predictions in high-risk lung cancer patients. Wikoff et al. ${ }^{18}$ also confirmed that there indeed exists the overexpression of Pro-SFTPB in the peripheral blood of NSCLC patients. This study examined the peripheral blood Pro-SFTPB in healthy volunteers and lung cancer patients, together with chest CT exami-nation, aiming to investigate whether this test indicator can be used as a specific tu-mor marker for the early 
screening of lung cancer.

\section{Methods}

This study was conducted in accordance with the declaration of Helsinki, and approval from the Ethics Committee of $5^{\text {th }}$ Hospital of Dalian. Written informed con-sent was obtained from all participants.

\section{Healthy volunteers and patients}

A total of 1000 volunteers were selected from the physical examination center of the Fifth People's Hospital of Dalian from January 2014 to September 2015. Addi-tionally, another 189 pathologically-diagnosed NSCLC patients (pathologically diag-nosed but not performed surgery, radiotherapy, or chemotherapy). A total of 127 healthy volunteers and 24 lung cancer patients were excluded due to not being regularly tested or lost. So, the cases that finally completed the experiment included a total of 873 healthy volunteers.

\section{Data of healthy volunteers and patients}

532 males and 341 females; 294 cases $>65$ years old and 579 cases $\leq 65$ years old; 657 cases with smoking index $>30$ packs/year and 294 cases with smoking index $\leq 30$ packs/year) and a total of 165 patients with lung cancer (including 102 males and 63 females; 97 cases $>65$ years old and 68 cases $\leq 65$ years old; 116 cases with smoking index $>30$ packs/year and 216 cases with smoking index $\leq 30$ packs/year (or non-smoking); 128 cases with adenocarcinoma and 37 cases with squamous cell carcinoma) (Table 1).

Table 1 - Data analysis of healthy volunteers and lung cancer patients.

\begin{tabular}{lccc}
\hline Item & Classification & Healthy volun-teers & Control group \\
Gender & $\mathrm{M}$ & 532 & 102 \\
Age & $\mathrm{F}$ & 341 & 63 \\
& $>65$ & 294 & 97 \\
Smoking index (including & $\leq 65$ & 579 & 68 \\
passive smoking) & $>30$ packs/year & 657 & 116 \\
Pathology & $\leq 30$ packs/year & 216 & 49 (or non-smoking) \\
& Adenocarcinoma & - & 128 \\
& Squamous cell & - & 37 \\
\hline
\end{tabular}

All of they were tested Pro-SFTPB in the peripheral blood (once every six months) by ELISA (the Pro-SFTPB ELISA kit is from Shanghai Jingbang Compony, China) and chest spiral CT (once a year) (the CT machine is produced by Siemens Compony of Germany) and followed up for two years.

\section{Inclusion criteria}

(1) Smoking, or quit smoking for less than 15 years, smoking index $>30$ packs/year, including passive smoking (long-term common life partner of a smoker, and the smoking amount was the same as the above); (2) Without a history of lung cancer or other cancers; (3) Volunteered to carry out the test and can cooperate with regular follow-up.

\section{Statistical analysis}

The $\chi^{2}$ test and multivariate correlation analysis were used, and the data pro-cessing was done using SPSS19.0. 


\section{- Results}

Positive rate of Pro-SFTPB of healthy volunteers and expression in lung cancer patients

The comparison between the positive rate of Pro-SFTPB in the healthy volun-teers and lung cancer patients showed that the positive rate in lung cancer patients was higher than $50 \%$, which was significantly higher than that in the healthy volun-teers, and the intergroup difference was statistically significant $(p \leq 0.05)$. The positive rate in the healthy volunteers did not change, while that in the lung cancer patients showed an increasing trend with the development of lung cancer (Table 2).

Table $\mathbf{2}$ - Comparative analysis of positive rate of Pro-SFTPB in healthy volunteers and lung cancer patients.

\begin{tabular}{lccc}
\hline Detection time & Healthy volunteers (\%) & Control group (\%) & $P$ \\
\hline $2014-3$ & $201(23.02)$ & $108(65.45)$ & $\leq 0.05$ \\
$2014-9$ & $172(19.70)$ & $97(58.79)$ & $\leq 0.05$ \\
$2015-3$ & $226(25.89)$ & $122(73.94)$ & $\leq 0.05$ \\
$2015-9$ & $182(20.85)$ & $116(70.30)$ & $\leq 0.05$ \\
\hline
\end{tabular}

Relationship of positive rate of Pro-SFTPB with patient features

Through analyzing the detection results of Pro-SFTPB of the twogroups, it can be seen that the positive rate of Pro-SFTPB was not related to the age and sex $(p>0.05)$. At the same time, the expression of Pro-SFTPB increased with the increase of smoking index, and the difference was statistically significant $(p \leq 0.05)$. The expressions of Pro-SFTPB in lung adenocarcinoma was significantly overexpressed than in $\mathrm{SqCa}$, and the intergroup difference was statistically significant $(p<0.05)$ (Table 3).

Table 3 - Relationship of positive rate of Pro-SFTPB with patient features

\begin{tabular}{lcccc}
\hline Item & Category & $\begin{array}{c}\text { Positive rate of } \\
\text { Pro-SFTPB (\%) }\end{array}$ & $X^{2}$ & $P$ \\
\hline Age & $>65$ & $120(30.69)$ & 0.4423 & $>0.05$ \\
Sex & $\leq 65$ & $186(28.75)$ & & $>0.8569$ \\
Smoking index & $\mathrm{M}$ & $196(30.91)$ & & $>0.05$ \\
Pathology & $>30$ packs/year & $241(27.23)$ & & \\
& $\leq 30$ packs/year & $65(24.62)$ & & \\
& $\begin{array}{c}\text { Adenocarcinoma } \\
\text { Squamous cell } \\
\text { carcinoma }\end{array}$ & $20(53.38)$ & 3.1966 & \\
& $91(71.09)$ & & $\leq 0.05$ \\
\hline
\end{tabular}


Positive rate of Pro-SFTPB in healthy volunteers and newly diagnosed lung cancer patients during follow-up

The CT follow-up revealed 6 cases of lung cancer in the first follow-up examina-tion and 5 cases of lung cancer in the second followup, and all the patients were pathologically diagnosed by surgery, biopsy, or bronchoscopy.
The 11 newly diag-nosed lung cancer patients were performed a total of 44-time Pro-SFTPB follow-up detection, and the comparison with the healthy volunteers revealed that the positive rate of Pro-SFTPB in these newly diagnosed lung cancer patients was $29.55 \%$, which was higher than the healthy volunteers (22.34\%), but no statistical significance was found ( $p>0.05$ ) (Table 4).

Table 4 - Comparison of positive rates of Pro-SFTPB between newly diagnosed lung cancer patients and healthy volunteers.

\begin{tabular}{lccc}
\hline Pro-SFTPB & $\begin{array}{c}\text { Newly diagnosed lung } \\
\text { cancer patients (\%) }\end{array}$ & Healthy volunteers (\%) & $P$ \\
\hline Positive rate & $13(29.55)$ & $195(22.34)$ & $>0.05$ \\
\hline
\end{tabular}

\section{- Discussion}

The total five-year survival rate of lung cancer is only $18.7 \%$ because of its hid-den symptoms and non-easy early detection ${ }^{13}$. So how to screen and early detect lung cancer has become the focus of medical fields over years. There exists an abnormal expression of SFTPB in lung cancer, especially in the adenocarcinoma cells, so Pro-SFTPB may be overexpressed. The level of blood Pro-SFTPB may be associated with certain lung cancer-independent known clinical risk factors. Therefore, the blood ProSFTPB level in individuals with high-risk lung can-cer may be used as a specific marker for the early diagnosis of lung cancer ${ }^{19}$.

Other studies ${ }^{20,21}$ have suggested that Napsin A is an important pre-gene of Pro-SFTPB. Brasch et $a .^{22}$ observed by immunoelectron microscopy that Napsin A, SP-B, and ProSFTPB are localized on the same position (lamellar body) of type II alveolar epithelial cells. Napsin A is a more specific marker of primary lung adenocarcinoma. Napsin A and free lamellar bodies can lead to the cleavage of three identical Pro-SFTPBs, suggesting that the expression deletion of Napsin A may increase the aggres-siveness of lung cancer, thereby affecting the prognosis of the disease. Furthermore, the expression deletion of Napsin A-caused the aggressiveness increase of lung cancer is due to its reducing the cleavage of Pro-SFTPB into mature SP-B, so its roles are reduced. Therefore, the increase of Pro-SFTPB in the peripheral blood is associated with the expression decrease of Napsin A. One report in the USA in 2013 pointed out that the incidence rate of high-risk population developing into lung cancer was $3 \%{ }^{18}$. The correlations of the mutation and expression of Pro-SFTPB gene with races are also reported ${ }^{23,24}$. Blood ProSFTPB tests have achieved initial results in North America, but whether it is applicable to Asian populations, especially for screening lung can-cer in Chinese populations, is our concern. In this study, the 873 healthy volunteers were also the people with high-risk lung cancer, and 2-year follow-up revealed 11 newly diagnosed lung cancer patients, and the incidence rate was $1.26 \%$, which was lower than that reported in the USA, but combined with the mean incidence of lung cancer in Dalian, this incidence is still 
higher than general populations by about 15 times and meets the epidemic law of lung cancer in Dalian area.

The results of this study showed that the level of Pro-SFTPB in the peripheral blood of lung cancer patients was significantly higher than the healthy volunteers, and the expression in lung adenocarcinoma was significantly higher than that in squamous cell carcinoma, thus further confirming that there exists abnormal SFTPB synthesis in NSCLC, especially in the adenocarcinoma cells, so Pro-SFTPB will be overexpressed. Matsui et al. ${ }^{25}$ examined the expressions of surfactant proteins and vascular endotheli-al growth factors in lung cancer patients and healthy people, and found that the above two indicators are clearly overexpressed in lung cancer, and higher in adenocarcinoma than in squamous cell carcinoma. There also exists a positive correlation with lung cancer stages, consistent with the findings of this study.

This study found that the Pro-SFTPB expression was significantly increased with the development of tumor progression, indicating that the overexpression of Pro-SFTPB may be an indirect manifestation of tumor invasion and development, which may provide a new idea for the follow-up observation and efficacy assessment of NSCLC.

Other studies have shown that the occurrence and development of tumors is inseparable from the local hypoxic environment, and too high $\mathrm{CO}_{2}$ concentration-caused local hypoxic environment can inhibit the synthesis of SFTPC, reduce the cell activity, and increase the apoptotic rate ${ }^{26}$, indicating that SFTPC may also be involved in the occurrence and development of tumors. However, the regulation of ProSFTPB is affected by cyclooxygenase-2 inhibitors. Cyclooxygenase-2 inhibitors may alleviate the inflammatory response by inhibiting prostaglandins, increase the cleavage of Pro-SFTPB, and increase the amount of mature SFTPB, thereby relieving lung injury under hyperoxic conditions, as well as reducing the possibility of tissue cell proliferation, which may also be an important mechanism for the occurrence and development of lung cancer, especially adenocarcinoma ${ }^{27}$.

In this study, the detection of Pro-SFTPB in newly discovered lung cancer pa-tients revealed that the positive rate was higher than the healthy volunteers, but no statistical difference can be found, indicating that ProSFTPB is not the only mecha-nism of lung cancer, and its occurrence and development is also interfered by many other tumor regulatory factors. Meanwhile, due to the small number of the samples enrolled in this study, the number of patients with lung cancer found in follow-up was also less and limited to one medical center of the Fifth People's Hospital in Dalian, which may be likely to cause the error and offset of the results. Therefore, although Pro-SFTPB in the peripheral blood can't be used as an alternative for screening and detecting NSCLC, as an important specific tumor marker of NSCLC, especially lung adenocarcinoma, it can provide more evidence-based medical evidence for the early diagnosis of lung cancer. Our next step is to confirm the possible roles of Pro-SFTPB in screening NSCLC by further enlarging largesample multi-center prospective studies.

\section{References}

1. Eberth JM. Lung cancer screening with low-dose CT in the United States. J Am Coll Radiol. 2015;12:1395-402. PMID: 26614885.

2. Teramoto A, Fujita $H$, Takahashi K, Yamamuro O, Tamaki T, Nishio M, Kobayashi T. Hybrid method for the detection of pulmonary nodules using positron emission tomography/computed tomography: a preliminary study. Int J Comput Assist Radiol Surg. 2014;9:59-69. PMID: 23793722.

3. Minamimoto $R$, Senda $M$, Jinnouchi $S$, Terauchi T, Yoshida T, Uno K, linuma $T$, Murano T, Nakashima R, Inoue T. Detection 
of lung cancer by FDG-PET cancer screening program: a nationwide Japanese survey. Anticancer Res. 2014;34:183-9. PMID: 24403460.

4. Buckens $C F$, van der Graaf $Y$, Verkooijen $\mathrm{HM}$, Mali WP, Isgum I, Mol CP, Ver-haar HJ, Vliegenthart $R$, Oudkerk $M$, van Aalst $C M$, de Koning HJ, de Jong PA. Osteoporosis markers on low-dose lung cancerscreening chest computed tomog-raphy scans predict allcause mortality. Eur Radiol. 2015;25:132-9. PMID: 25323601.

5. Watts JR, Sonavane SK, Snell-Bergeon J, Nath $\mathrm{H}$. Visual scoring of coronary artery calcification in lung cancer screening computed tomography: association with all-cause and cardiovascular mortality risk. Coron Artery Dis. 2015;26:157-62. PMID: 25370000.

6. Gates TJ. Screening for cancer: concepts and controversies. Am Fam Physician. 2014; 90:625-31. PMID: 25368922.

7. Screening for lung cancer. Too many uncertainties, even for smokers. Prescrire Int. 2014;23:19-23. PMID: 24516909.

8. Taivans I, Bukovskis M, Strazda G, Jurka N. Breath testing as a method for de-tecting lung cancer. Expert Rev Anticancer Ther. 2014;14:121-3. PMID: 24467216.

9. He WJ, Li WH, Jiang B, Wang YF, Xia YX, Wang L. MicroRNAs level as an initial screening method for early-stage lung cancer: a bivariate diagnostic ran-dom-effects metaanalysis. Int J Clin Exp Med. 2015;8:1231726. PMID: 26550141.

10.Moein $M M$, Javanbakht $M$, Karimi $M$, Akbari-adergani B, Abdel-Rehim M. A new strategy for surface modification of polysulfone membrane by in situ im-printed sol-gel method for the selective separation and screening of L-Tyrosine as a lung cancerbiomarker. Analyst. 2015;140:193946. PMID: 25664351.

11.Lim JH, Park J, Oh EH, Ko HJ, Hong S, Park TH. Nanovesicle-based bioelec-tronic nose for the diagnosis of lung cancer from human blood. Adv Healthc Ma-ter. 2014;3:360-6. PMID: 23868879.

12. Hirales Casillas CE, Flores Fernández JM,
Padilla Camberos E, Herrera López EJ, Leal Pacheco G, Martínez Velázquez M. Current status of circulating protein bi-omarkers to aid the early detection of lung cancer. Future Oncol. 2014;10:1501-13. PMID: 25052758.

13. Hamvas A, Heins HB, Guttentag SH, Wegner DJ, Trusgnich MA, Bennet KW, Yang P, Carlson $\mathrm{CS}, \mathrm{An} \mathrm{P}$, Cole FS. Developmental and genetic regulation of hu-man surfactant protein $B$ in vivo. Neonatology. 2009;95:117-24. PMID: 18776725.

14.Griese $M$, Schumacher $S$, Tredano $M$, Steinecker M, Braun A, Guttentag S, Beers $M F$, Bahuau M. Expression profiles of hydrophobic surfactant proteins in children with diffuse chronic lung disease. Respir Res. 2005;6:80. PMID: 16042774.

15.Emr BM, Roy S, Kollisch-Singule M, Gatto LA, Barravecchia M, Lin X, Young JL, Wang G, Liu J, Satalin J, Snyder K, Nieman GF, Dean DA. Electroporation-mediated gene delivery of $\mathrm{Na}+, \mathrm{K}+-$ ATPase, and ENaC subunits to the lung at-tenuates acute respiratory distress syndrome in a two-hit porcine model. Shock. 2015;43:16-23. PMID: 25004064.

16.Czernik C, Schmalisch G, Bührer C, Proquitté $\mathrm{H}$. Fetal and neonatal samples of a precursorsurfactant protein B inversely related to gestational age. BMC Pediatr. 2013;13:164. PMID: 24112641.

17.Leung JM, Mayo J, Tan W, Tammemagi CM, Liu G, Peacock S, Shepherd FA, Goffin J, Goss G, Nicholas G, Tremblay A, Johnston $M$, Martel S, Laberge F, Bhatia R, Roberts $H$, Burrowes $P$, Manos $D$, Stewart L, Gingras M, Pasian S, Tsao MS, Lam S, Sin DD; PanCanadian Early Lung Cancer Study Group. Plas-ma pro-surfactant protein B and lung function decline in smokers. Eur Respir J. 2015;45:1037-45. PMID: 25614175.

18.Wikoff WR, Hanash S, DeFelice B, Miyamoto S, Barnett M, Zhao Y, Goodman G, Feng Z, Gandara D, Fiehn O, Taguchi A. Diacetylspermine is a novel prediag-nostic serum biomarker for non-small-cell lung cancer and has additive perfor-mance with pro-surfactant protein B. J Clin Oncol. 2015;33:3880-6. PMID: 26282655.

19.Taguchi A, Hanash S, Rundle A, McKeague 
IW, Tang D, Darakjy S, Gaziano JM, Sesso HD, Perera F. Circulating pro-surfactant protein B as a risk biomarker for lung cancer. Cancer Epidemiol Biomarkers Prev. 2013;22:175661. PMID: 23897585.

20.Suzuki A, Shijubo N, Yamada G, Ichimiya S, Satoh M, Abe S, Sato N. Napsin A is useful to distinguish primary lung adenocarcinoma from adenocarcinomas of other organs. Pathol Res Pract. 2005;201:579-86. PMID: 16259111.

21.Zhang P, Han YP, Huang L, Li Q, Ma DL. Value of Napsin A and thyroidtran-scrption factor-1 in the identification of primary lung adenocarcinoma. Oncol Lett. 2010;1:899903. PMID: 22966403.

22. Brasch F, Ochs M, Kahne T, Guttentag S, Schauer-Vukasinovic V, Derrick $M$, Johnen G, Kapp N, Muller KM, Richter J, Giller T, Hawgood S, Buhling F. In-volvement of napsin $A$ in the $C$ - and N-terminal processing of surfactant protein B in type-II pneumocytes of the human lung. J Biol Chem. 2003;278:49006-14. PMID: 13129928.

23.El-Telbany A, Ma PC. Cancer genes in lung cancer: racial disparities: are there any? Genes Cancer. 2012;3:467-80. PMID:
23264847.

24.Giovino GA, Mirza SA, Samet JM, Gupta PC, Jarvis MJ, Bhala N, Peto R, Za-tonski W, Hsia J, Morton J, Palipudi KM, Asma S; GATS Collaborative Group. Tobacco use in 3 billion individuals from 16 countries: an analysis of nationally representative cross-sectional household surveys. Lancet. 2012;380:66879. PMID: 22901888.

25. Matsui $Y$, Amano $H$, Ito $Y$, Eshima $K$, Tamaki $H$, Ogawa $F$, lyoda $A$, Shibuya $M$, Kumagai Y, Satoh Y, Majima M. The role of vascular endothelial growth factor receptor-1 signaling in compensatory contralateral lung growth following unilat-eral pneumonectomy. Lab Invest. 2015;95:45668. PMID: 25642830.

26.Liu X, Feng Z, Tian C, Kong X, Wu Y, Lv C. Effect of keratinocyte growth fac-tor on growth and transdifferentiation of primary alveolar epithelial type II cells. Turk J Med Sci. 2015;45:251-60. PMID: 26084112.

27. Mittal N, Sanyal SN. Cycloxygenase inhibition enhances the effects of surfactant therapy in endotoxin-induced rat model of ARDS. Inflammation. 2011;34:92-8. PMID: 20422273.

\section{Correspondence:}

Yong $\mathrm{He}$

Department of Thoracic Surgery

$5^{\text {th }}$ People's Hospital of Dalian

Dalian 116021, China

Phone: +86 41184211244

Fax: +8641184214794

docyonghe@163.com

Received: Mar 13, 2017

Review: May 15, 2017

Accepted: June 14, 2017
Conflict of interest: none

Financial source: Fund Program of Dalian City (№ 2014E14SF157)

\begin{abstract}
${ }^{1}$ Research performed at Department of Thoracic Surgery, Clinical Laboratory, $5^{\text {th }}$ People's Hospital of Da-lian, China.
\end{abstract}

